\title{
BMJ Open R/S Atlas: Identifying existing cohort study data resources to accelerate epidemiological research on the influence of religion and spirituality on human health
}

Anna Boonin Schachter (D) , ${ }^{1}$ M Austin Argentieri (D) , ${ }^{1,2}$ Bobak Seddighzadeh, ${ }^{1,3}$ Oluwaseyi O Isehunwa (D) ,1,4 Blake Victor Kent (D) , , ${ }^{1,4,5}$ Philip Trevvett, ${ }^{4}$ Michael McDuffie, ${ }^{1}$ Laura Mandel, ${ }^{6}$ Kenneth I Pargament, ${ }^{7}$ Lynn G Underwood, ${ }^{8}$ Alexa T McCray (D) , ${ }^{4}$ Alexandra E Shields ${ }^{1,4}$

To cite: Schachter $A B$, Argentieri MA, Seddighzadeh B, et al. RIS Atlas: Identifying existing cohort study data resources to accelerate epidemiological research on the influence of religion and spirituality on human health. BMJ Open 2021;11:e043830. doi:10.1136/ bmjopen-2020-043830

- Prepublication history for this paper is available online. To view these files, please visit the journal online (http://dx.doi org/10.1136/bmjopen-2020043830).

Received 18 September 2020 Accepted 16 September 2021

Check for updates

(c) Author(s) (or their employer(s)) 2021. Re-use permitted under CC BY-NC. No commercial re-use. See rights and permissions. Published by BMJ.

For numbered affiliations see end of article.

Correspondence to Anna Boonin Schachter; abschachter@mgh.harvard.edu

\section{ABSTRACT}

Objective Many studies have documented significant associations between religion and spirituality (R/S) and health, but relatively few prospective analyses exist that can support causal inferences. To date, there has been no systematic analysis of R/S survey items collected in US cohort studies. We conducted a systematic content analysis of all surveys ever fielded in 20 diverse US cohort studies funded by the National Institutes of Health (NIH) to identify all R/S-related items collected from each cohort's baseline survey through 2014.

Design An RIS Ontology was developed from our systematic content analysis to categorise all R/S survey items identified into key conceptual categories. A systematic literature review was completed for each $\mathrm{R} / \mathrm{S}$ item to identify any cohort publications involving these items through 2018.

Results Our content analysis identified 319R/S survey items, reflecting 213 unique R/S constructs and 50 RIS Ontology categories. 193 of the 319 extant $\mathrm{R} / \mathrm{S}$ survey items had been analysed in at least one published paper. Using these data, we created the RIS Atlas (https://atlas.mgh.harvard.edu/), a publicly available, online relational database that allows investigators to identify R/S survey items that have been collected by US cohorts, and to further refine searches by other key data available in cohorts that may be necessary for a given study (eg, race/ethnicity, availability of DNA or geocoded data).

Conclusions RIS Atlas not only allows researchers to identify available sources of R/S data in cohort studies but will also assist in identifying novel research questions that have yet to be explored within the context of US cohort studies.

\section{INTRODUCTION}

Over the past 20 years, religion and spirituality $(\mathrm{R} / \mathrm{S})$ have been increasingly recognised as important resources for

\section{Strengths and limitations of the study}

- We conducted a systematic analysis of religion and spirituality $(\mathrm{R} / \mathrm{S})$ survey items collected by a group of 20 US National Institutes of Health funded cohort studies to create a publicly available, online searchable database (RIS Atlas; https://atlas.mgh.harvard. edu).

- Cohorts included in RIS Atlas include diverse participant populations and contain a wide range of measures on clinical and health outcomes.

- RIS Atlas allows researchers to search for R/S items that are available in existing US cohort studies and that could be used to conduct immediate prospective analyses.

- RIS Atlas will also assist in identifying novel R/S research questions that have yet to be explored within the context of US cohort studies.

resilience that have both protective and deleterious effects on human health. ${ }^{12}$ Measures of $\mathrm{R} / \mathrm{S}$ have been prospectively associated with several mental health outcomes, including reduced risk of depression, ${ }^{3} 4$ anxiety or emotional distress, ${ }^{5}$ and risk of suicidal attempts. ${ }^{67}$ Prospective analyses of chronic disease risk have associated various measures of $\mathrm{R} / \mathrm{S}$ with lower blood pressure and reduced risk of hypertension, ${ }^{8} 9$ cardiovascular events, ${ }^{10}$ obesity, ${ }^{11}$ mortality ${ }^{12-14}$ and higher self-rated health. ${ }^{15-18}$ Multiple studies, including several randomised controlled trials, have shown that spiritual practices such as yoga and meditation increase expression of genes associated with enhanced mitochondrial function and insulin secretion, and reduce 
expression of genes linked to inflammation and the stress response. ${ }^{19-22}$ Additional research is needed, however, to identify the mechanisms or pathways through which other dimensions of R/S may work to influence risk of disease.

Despite promising advancements, $\mathrm{R} / \mathrm{S}$ research has been hampered by the relatively few high-quality prospective studies conducted with adequate sample sizes, the limited dimensions of $\mathrm{R} / \mathrm{S}$ assessed and the predominance of white, Christian study populations. A systematic review of studies published from 2000 to 2010 assessing R/S influences on depression, for example, found that only 45 of 339 extant studies were prospective, and several of these were rated as poor quality despite their prospective study design. ${ }^{2}$ The relatively small number of prospective studies on $\mathrm{R} / \mathrm{S}$ and health is due, in part, to a lack of $\mathrm{R} / \mathrm{S}$ survey items routinely collected by US cohort studies. Currently, very few cohort studies collect more than a few R/S items, and, when they do, a scientific rationale for item selection is often lacking. ${ }^{23}$ Many $\mathrm{R} / \mathrm{S}$ survey items collected by cohorts have also never been analysed due to a lack of National Institutes of Health (NIH) funding in this area. ${ }^{23}$ In $2019, \mathrm{R} /$ S-related research received approximately $0.2 \%$ of all awarded NIH research dollars.

No study to date has systematically assessed which R/S survey items have been collected by US cohort studies and are currently available to support prospective analyses of $\mathrm{R} / \mathrm{S}$ influences on health. To address this gap in the literature and to facilitate prospective analyses investigating the influence of $\mathrm{R} / \mathrm{S}$ on health, we: (1) conducted a content analysis of all surveys ever fielded by 20 NIH-funded US cohort studies, in order to identify all R/S-related survey items fielded from each cohort's inception through 2014; (2) developed an RIS Ontology that maps all of the R/Sitems identified in our content analysis into a hierarchy of theologically meaningful conceptual categories; (3) conducted a systematic review to identify which of these $\mathrm{R} / \mathrm{S}$ items have been analysed in a published study and (4) created RIS Atlas, a platform that organises all of this information into an open-access, searchable, online research tool to facilitate prospective $\mathrm{R} / \mathrm{S}$ analyses and advance understanding of the influence of $\mathrm{R} / \mathrm{S}$ on the human health.

\section{METHODS}

\section{Selection of cohorts}

We generated a list of 35 NIH-funded cohort studies, prioritising cohorts for inclusion in this list that represented diverse racial/ethnic communities (in order to support disparities-focused research), as well as cohorts representing diverse clinical outcomes and large, national samples. Outreach to principal investigators (PIs) of these 35 cohorts was conducted until 20 PIs agreed to have their cohorts included in this analysis.

\section{Content analysis of cohorts' survey instruments}

All primary survey instruments, and as many ancillary instruments as possible, were collected from these 20 cohorts by use of study websites and/or assistance from cohort investigators. Surveys encompassed each cohort's first round of data collection through to their latest survey (through 2014), regardless of survey administration method (ie, online, mail or in-person) or population (eg, the full cohort or a subpopulation, such as an ancillary study). These surveys were then examined via a systematic content analysis to identify all $\mathrm{R} / \mathrm{S}$ items ever administered in each cohort.

Research assistants reviewed each survey instrument and recorded all survey items related to R/S, specifically looking for questions or response categories containing words or cognates of spirituality, religion, faith, God, higher power, divine, church, worship, Sabbath, prayer, congregation, clergy, priest or meditation. Survey items were considered $\mathrm{R} / \mathrm{S}$ in nature if the question, response category or section header contained R/S-related content. The inclusion of each item, as well as the recorded contextual information related to each $\mathrm{R} / \mathrm{S}$ survey item (eg, source instrument, study population in which the question was fielded, full question and response categories) and key cohort characteristics (eg, year of inception; sample size; composition of cohort by race/ethnicity, sex and age; and whether the cohort was geocoded and/ or collected DNA samples) were checked by a second reviewer and any differences reconciled.

The basic unit of information extracted from cohort surveys to include as searchable items in RIS Atlas were individual R/S items from the surveys, regardless of format in which they were collected or asked. Depending on the cohort and the survey, an item might be a standalone measure, a subitem from a larger scale or a response category from a survey question (eg, an R/S-related response category from a question asking the respondent to "mark all that apply'). Each R/S-related response category in a 'mark all that apply' question was considered a different item to add to RIS Atlas. The same question asked to the same cohort population in multiple years was classified as a single item (users can see 'years asked' information for each item within RIS Atlas to identify repeated items for each cohort). However, the same question asked by different cohorts, or even the same question asked to different groupings within the same cohort (eg, a cohort's full exam vs that cohort's ancillary study sub-population), was classified as separate individual items for the purpose of this content analysis. Likewise, questions similar in meaning but using different wording or response categories were also counted as multiple individual items. Classifying and counting survey items in this way was necessary in order to ensure that RIS Atlas conveys the full scope of $\mathrm{R} / \mathrm{S}$ information collected and available in each cohort at the most granular level possible.

To allow researchers to understand the number of unique R/S constructs that each cohort has collected, however, we also collapsed groups of individual R/S 
survey items that are functionally identical or repeated (by the same cohort, different cohorts or different cohort subgroups) into larger units of unique, non-overlapping constructs ('unique R/S constructs'). Examples of these unique R/S constructs include 'how often do you attend religious services or organised religious activities?' (which combines individual R/S survey items such as 'how often do you go to religious meetings or services?' or 'how often do you attend church or other religious meetings?') and 'what is your religious affiliation?' (which combines individual $\mathrm{R} / \mathrm{S}$ survey items such as "what religion would you identify yourself with?' or 'what is your religious affiliation?'). Grouping items by unique R/S constructs provides a heuristic way to count units of information contained in RIS Atlas that are unique, non-overlapping $\mathrm{R} / \mathrm{S}$ constructs. Additional work will need to be done to analytically harmonise the items within these unique constructs across cohorts prior to being used in analyses.

\section{Development of the RIS Ontology}

Based on our content analysis, and drawing from published literature and input from $\mathrm{R} / \mathrm{S}$ and informatics experts, we developed an RIS Ontology that organises the diverse $\mathrm{R} / \mathrm{S}$ information we identified into theologically meaningful concepts and categories. As new R/S items were collected throughout our content analysis, we iteratively refined our RIS Ontology by mapping each R/S item onto our initial high-level concepts, and then adding, removing or merging concepts in the RIS Ontology as needed so that all items would be captured by a category. We also created subcategories (eg, dividing 'coping' into 'religious coping' and 'spiritual coping'), where appropriate, to further refine the RIS Ontology. Throughout this process, input was provided by $\mathrm{R} / \mathrm{S}$ and informatics experts and further adjustments made until all identified $\mathrm{R} / \mathrm{S}$ items across all 20 cohorts were mapped onto theologically coherent categories and subcategories in the RIS Ontology.

\section{Systematic review of RIS Atlas items used in published analyses}

We then performed a systematic literature review (of articles published through 2018) for each R/S item collected in each cohort. We conducted a separate systematic review in PubMed for each item in the RIS Atlas using a search string that combined keywords from the item with the name of the cohort in which it was administered. All article titles and abstracts were screened from each search, and any article that included an item from the RIS Atlas as an analysis variable was included in our final list. Articles were not screened further, nor excluded based on analysis type or study findings. No analysis of the content of the articles, beyond whether an RIS Atlas item was used as an analysis variable, was carried out. This process resulted in an exhaustive list of publications (if any) resulting from the collection of each $\mathrm{R} / \mathrm{S}$ survey item in each of the 20 cohorts.

\section{Development of the RIS Atlas query tool}

Once all R/S items were identified from cohort surveys and classified according to our RIS Ontology, we incorporated them (along with the cohort data we had collected) into an online relational database called 'RIS Atlas'. To make this a functional and broadly useful tool, we worked with informatics and web design experts to develop RIS Atlas' foundational structure, search algorithms and user interface.

\section{Patient and public involvement}

No patients or members of the public were involved in the design or recruitment of our study, nor in the dissemination of results.

\section{RESULTS}

\section{Content analysis}

In total, we analysed more than 200 survey instruments, representing thousands of pages and up to 67 years (19482014) of data collection. We identified a total of 319 individual R/S survey items across all cohorts, each of which is searchable in RIS Atlas as a discrete piece of information. The cohort collecting the most individual R/S survey items was the Adventist Health Study-2 (AHS-2; n=147), followed by the Hispanic Community Health Study/Study of Latinos (HCHS/SOL; $\mathrm{n}=38$ ). Aside from the religionfocused AHS-2, only 172 R/S survey items have been collected across all of the remaining 19 cohorts. Thirteen cohorts collected 5 or more R/S survey items, and only 7 cohorts collected 10 or more items. After reviewing all R/S survey items for conceptual overlap, we arrived at a list of 213 unique $\mathrm{R} / \mathrm{S}$ constructs collected across all cohorts. See table 1 for a complete list of participating cohort studies, their year of inception and the number of individual $\mathrm{R} / \mathrm{S}$ survey items and unique $\mathrm{R} / \mathrm{S}$ constructs collected per cohort.

We identified 16 validated scales through our content analysis, represented (either in full or via selected subitems used on surveys) by $193 \mathrm{R} / \mathrm{S}$ survey items. The scales most commonly represented by items in the RIS Atlas were the Functional Assessment of Chronic Illness Therapy-Spiritual Well-being Expanded Version (FACITSp-Ex; n=41) and the Religious Coping Scale (RCOPE; $\mathrm{n}=31$ ). See table 2 for the validated scales represented in RIS Atlas (including citations and the number of $\mathrm{R} / \mathrm{S}$ survey items and unique $\mathrm{R} / \mathrm{S}$ constructs that relate to each scale).

\section{RIS Ontology}

The RIS Ontology comprises 50 concepts distributed across 12 high-level categories. Ontology categories most often captured by extant cohort R/S survey items were religious coping $(\mathrm{n}=38)$, religious meetings or services $(\mathrm{n}=22)$ and quality of relationships among religious community members $(\mathrm{n}=22)$. Table 3 presents our final $\mathrm{R} I \mathrm{~S}$ Ontology and the number of R/S survey items and unique $\mathrm{R} / \mathrm{S}$ constructs included in the RIS Atlas that map 
Table 1 Twenty cohort studies participating in R|S Atlas (as well as the year each cohort began and the number of individual $\mathrm{R} / \mathrm{S}$ survey items and unique R/S constructs collected by each cohort), through 2014

\begin{tabular}{lccc}
\hline Cohort study name & $\begin{array}{l}\text { Year } \\
\text { initiated }\end{array}$ & $\begin{array}{c}\text { Individual R/S } \\
\text { survey items }\end{array}$ & $\begin{array}{c}\text { Unique R/S } \\
\text { constructs }^{*}\end{array}$ \\
\hline Adventist Health Study-2 (AHS-2) & 2002 & 147 & 128 \\
Black Women's Health Study (BWHS) & 1995 & 8 & 7 \\
Cancer Prevention Study II (CPS II) & 1982 & 3 & 2 \\
California Teachers Study (CTS) & 1995 & 5 & 5 \\
\hline Framingham Heart Study (FHS) & 1948 & 10 & 9 \\
\hline Hispanic Community Health Study/Study of Latinos (HCHS/SOL) & 2008 & 38 & 35 \\
\hline Health Professionals Follow-Up Study (HPFS) & 1986 & 7 & 4 \\
\hline Jackson Heart Study (JHS) & 2000 & 13 & 12 \\
\hline Mediators of Atherosclerosis in South Asians Living in America (MASALA) & 2010 & 3 & 3 \\
\hline Multiethnic Cohort Study of Diet and Cancer (MEC) & 1993 & 1 & 1 \\
\hline Multi-Ethnic Study of Atherosclerosis (MESA) & 2000 & 13 & 11 \\
Nurses' Health Study I (NHS I) & 1976 & 2 & 2 \\
\hline Nurses' Health Study II (NHS II) & 1989 & 16 & 14 \\
\hline Prostate, Lung, Colorectal, and Ovarian Cancer Screening Trial (PLCO) & 1993 & 1 & 1 \\
\hline Project Viva & 1999 & 3 & 3 \\
\hline Southern Community Cohort Study (SCCS) & 2002 & 7 & 7 \\
\hline Strong Heart Study (SHS) & 1989 & 7 & 7 \\
\hline The Sister Study & 2004 & 7 & 5 \\
\hline Women's Health Initiative (WHI) & 1993 & 25 & 15 \\
\hline Women's Health Study (WHS) & 1993 & 3 & 2 \\
\hline
\end{tabular}

*As some R/S constructs were collected by multiple cohorts, the R/S constructs column sum is more than the $213 \mathrm{R} / \mathrm{S}$ constructs identified by our content analysis.

$\mathrm{R} / \mathrm{S}$, religion and spirituality.

onto each Ontology category. As this table shows, many concepts have rarely been asked among our sample of cohorts.

\section{RIS Atlas items analysed in previously published analyses}

We identified a total of 104 publications that analysed $193 \mathrm{R} / \mathrm{S}$ survey items contained in RIS Atlas. The greatest number of publications was related to the categories of religious service attendance $(\mathrm{N}=39)$ and religious and spiritual coping $(\mathrm{N}=23)$. The AHS-2 had the most $\mathrm{R} / \mathrm{S}$ publications $(\mathrm{N}=18$, assessing a total of 101 individual $\mathrm{R} / \mathrm{S}$ survey items), while the remaining 19 cohorts published a total of 86 studies examining $\mathrm{R} / \mathrm{S}$ survey items included in the Atlas.

\section{RIS Atlas query tool}

We integrated our RIS Ontology, cohort characteristics and R/S items identified through our content analysis into an open-access data resource, RIS Atlas (https:// atlas.mgh.harvard.edu). The RIS Atlas database is also archived permanently with more limited search functionality in the Harvard Dataverse (https://doi.org/ $10.7910 / \mathrm{DVN} / 6 \mathrm{WFCL} 5)$. The cohort is the unit of analysis represented in RIS Atlas. The RIS Atlas query tool search options include searching by keyword, searching via a Boolean drag-and-drop feature and filtering results by keyword. Once searches are complete, users may also sort search results according to different criteria. The search functions provided by RIS Atlas are designed to help researchers identify which $\mathrm{R} / \mathrm{S}$ items are available in which cohorts, so that they may contact those cohorts to request access to individual-level data.

The RIS Ontology, which forms the backbone of the RIS Atlas, provides a user-friendly way for investigators new to $\mathrm{R} / \mathrm{S}$ research to find data, as they need not know the specific R/S terms that apply to their research; rather, they may simply select categories represented in the Ontology to search for survey items contained within that category. For example, selecting the Ontology concept of 'private religious practices' would retrieve many different types of survey items, for example, 'how often do you pray?' (Black Women's Health Study; BWHS); 'I pray or meditate (not at all, a little, medium or a lot)' (Nurses' Health Study II; NHS II) and 'how often do you spend time in private religious activities, such as prayer, meditation or Bible study?' (HCHS/SOL). 
Table 2 Sixteen validated scales represented in R/S Atlas (and the number of individual R/S survey items and unique R/S constructs that fall under each scale), through 2014

\begin{tabular}{|c|c|c|}
\hline Validated scale & $\begin{array}{l}\text { Individual R/S } \\
\text { survey items* }\end{array}$ & $\begin{array}{l}\text { Unique R/S } \\
\text { constructs* }\end{array}$ \\
\hline Berkman-Syme Social Network Index ${ }^{30}$ & 16 & 5 \\
\hline Brief Multidimensional Measure of Religiousness/Spirituality (BMMRS) $)^{31} 32$ & 24 & 19 \\
\hline Congregational Sense of Community ${ }^{33}$ & 10 & 10 \\
\hline COPE Inventory ${ }^{34}$ & 2 & 2 \\
\hline Coping Strategies Inventory-Short Form (CSI-SF) ${ }^{35}$ & 1 & 1 \\
\hline Daily Spiritual Experiences Scale (DSES) ${ }^{36}$ & 15 & 11 \\
\hline Duke University Religion Index (DUREL) $)^{37}$ & 8 & 6 \\
\hline $\begin{array}{l}\text { Functional Assessment of Chronic Illness Therapy-Spiritual Well-being Expanded } \\
\text { Version (FACIT-Sp-Ex) }\end{array}$ & 41 & 25 \\
\hline Gratitude Questionnaire (GQ-6) $)^{39}$ & 6 & 6 \\
\hline Healthcare Preferences Questionnaire ${ }^{40}$ & 2 & 2 \\
\hline Jackson Heart Study Discrimination Instrument (JHSDIS) $)^{41}$ & 2 & 1 \\
\hline Multiphasic Assessment of Cultural Constructs-Short Form (MACC-SF) ${ }^{42}$ & 1 & 1 \\
\hline Religious Coping Scale (RCOPE) $)^{43}$ & 31 & 29 \\
\hline Sabbath and Endtime Scale & 20 & 13 \\
\hline Spiritual Meaning Scale ${ }^{44}$ & 5 & 5 \\
\hline Structure of Prayer ${ }^{45}$ & 9 & 9 \\
\hline
\end{tabular}

${ }^{*}$ As not all R/S survey items are from a scale, the column sums are less than the $319 \mathrm{R} / \mathrm{S}$ survey items and $213 \mathrm{R} / \mathrm{S}$ constructs identified by our content analysis.

$\mathrm{R} / \mathrm{S}$, religion and spirituality.

RIS Atlas also allows users to simultaneously crossreference R/S survey items with demographic characteristics of cohorts (eg, religious coping survey items administered in African American or female populations), and/or query a number of demographic characteristics (eg, age, sex or racial/ethnic composition) and other key cohort characteristics (eg, availability of geocoded data or DNA samples). Lastly, the RIS Atlas query tool retrieves information from our literature review, which allows investigators to identify new, unstudied research questions for each Atlas item that could be immediately pursued.

The RIS Atlas website includes descriptions and links for each of the participating cohorts (via the 'Cohorts' page) to facilitate investigators directly contacting individual cohorts that have the data they need to support their proposed analysis, and includes a 'Resources' page that provides additional information and links on established scales represented in the Atlas, citations and links for cohorts' publications that use R/S survey items in the Atlas, and links to some additional web resources related to $\mathrm{R} / \mathrm{S}$ research.

\section{DISCUSSION}

Advancing knowledge regarding the role of $\mathrm{R} / \mathrm{S}$ in health will likely require a two-pronged approach: (1) maximising the usefulness of existing data to assess the influence of $\mathrm{R} / \mathrm{S}$ on diverse health outcomes and (2) persuading individual cohorts to collect additional $\mathrm{R} / \mathrm{S}$ survey items to support prospective studies on a wider array of $\mathrm{R} / \mathrm{S}$ variables. Our work, culminating in the development of RIS Atlas, helps address each of these challenges.

First, the searchable nature of RIS Atlas will help researchers identify existing $\mathrm{R} / \mathrm{S}$ survey items that could be used immediately to conduct prospective studies investigating the influence of $\mathrm{R} / \mathrm{S}$ on various clinical endpoints. RIS Atlas allows researchers to identify novel analyses, focusing on unstudied R/S items, clinical outcomes or cohort populations. RIS Atlas will also aid users in identifying $\mathrm{R} / \mathrm{S}$ items available across several cohorts, which will facilitate comparative, pooled or meta-analyses. For example, the RIS Atlas shows that NHS II, HCHS/SOL, Multi-Ethnic Study of Atherosclerosis (MESA) and Women's Health Initiative (WHI) are among the cohorts having collected a survey item on religious service attendance; investigators could, therefore, propose to conduct robust, comparative analyses on religious service attendance and health across a large and diverse set of white, black, Hispanic/Latino and Asian cohort participants.

Second, the relatively low number of different dimensions of $\mathrm{R} / \mathrm{S}$ measured by this sample of 20 cohorts (table 1) illustrates the need to expand the 
Table 3 Structure of the R/S Ontology (and the number of individual R/S survey items and unique R/S constructs mapping on to each category), through 2014

\section{Ontology category}

Individual R/S survey items $\dagger$ Unique R/S constructs $\dagger$

Religious or spiritual identity or affiliation

Current denomination or affiliation of self *

Denomination or affiliation of family members

113

Denomination or affiliation raised in

Self-described religiosity or spirituality

$8 \quad 6$

Denomination or affiliation of people you spend time with

1

$\begin{array}{ll}10 & 8 \\ 4 & 4\end{array}$

Characteristics of religious community

Size of religious community

\section{Religious practices}

Private religious practices

Private prayer or meditation

Private reading of Holy scriptures or writings

Motivation for private religious practice

Communal religious practices

Religious meetings or services

Communal prayer or meditation

Community leadership

Service to others

Faith-based group or institution

Cultural religious practices or norms

\section{Religious experiences}

Belief or conceptions of God or a Divine Being

Feel or desire a greater union with God or a Divine Being

Feel the presence of God or a Divine Being

Conversion experience

Religion as a source of strength, comfort, or joy

*

3

6

1

8

Religious discrimination

Struggle with religious beliefs or conceptions of God or a 5

Divine Being

\section{Spiritual experiences}

Spirituality as a source of strength, comfort, or joy

4

Spiritual connection, peace, or harmony 13

\section{Support}

Religious support

Spiritual support

2

3

2

3

$17 \quad 11$

$\begin{array}{ll}3 & 3 \\ 7 & 2\end{array}$

7

$8 \quad 5$

$\begin{array}{ll}22 & 4 \\ 1 & 1\end{array}$

1 1

3

$\begin{array}{ll}2 & 2 \\ 8 & 6 \\ 10 & 10\end{array}$

Quality of relationships among religious community members 22

Coping 11

$\begin{array}{lll}\text { Religious coping } & 38 & 33 \\ \text { Spiritual coping } & 6 & 5 \\ \text { Meaning } & 17 & 11 \\ \text { Forgiveness } & 1 & 1 \\ \text { Forgiving self } & 2 & 2 \\ \text { Forgiving others } & 3 & 2 \\ \text { Experience of being forgiven by God or a Divine Being } & 4 & 3\end{array}$

Continued 
Table 3 Continued

\begin{tabular}{lll}
\hline Ontology category & Individual R/S survey items† & Unique R/S constructs† \\
\hline Gratitude & 8 & 6 \\
Centrality of faith or spirituality to one's life & 8 & 5 \\
Religious or spiritual beliefs affecting medical decision- & $*$ & $*$ \\
making & 5 & 5 \\
$\quad$ End of life decisions & 1 & 1 \\
$\quad$ Treatment choices & 5 & 5 \\
$\quad$ Traditional faith healers & 10 & 8 \\
$\quad$ Spiritual healing & 5 & \\
\hline
\end{tabular}

*Although some parent categories have R/S survey items or constructs mapped directly to them (instead of, or in addition to, survey items or constructs being mapped to their subcategories), these parent categories do not have any R/S survey items or constructs mapped directly to them, only to their subcategories.

$\dagger$ As some R/S survey items and constructs map to multiple Ontology categories, the column sums are more than the $319 \mathrm{R} / \mathrm{S}$ survey items and $213 \mathrm{R} / \mathrm{S}$ constructs identified by our content analysis.

$\mathrm{R} / \mathrm{S}$, religion and spirituality.

collection of $\mathrm{R} / \mathrm{S}$ data in cohort studies in order to understand the complex ways in which $\mathrm{R} / \mathrm{S}$ affect human health. RIS Atlas demonstrates that there are several important dimensions of $\mathrm{R} / \mathrm{S}$ that are undercollected in US cohorts (tables 2 and 3 ). Survey items addressing more functional aspects of $\mathrm{R} / \mathrm{S}$, such as using positive religious coping, and even negative $\mathrm{R} / \mathrm{S}$ experiences such as spiritual struggles and negative religious coping, ${ }^{24-29}$ may be especially significant $\mathrm{R} / \mathrm{S}$ influences affecting the aetiology of disease that remain understudied.

This study has several limitations that should be noted. First, our cohort sample was not random. While the results may not be generalisable to all US cohorts, our cohorts represent a variety of clinical conditions, racial/ethnic communities and regions of the USA. Second, while we are confident that our content analysis included all surveys of each cohorts' main study populations, cohorts varied in their ability to identify and provide survey instruments for past ancillary studies. Thus, some R/S survey items collected by smaller ancillary studies may not be included. Third, while we made efforts to include cohorts that represented diverse racial/ethnic communities, these 20 cohorts do not include all subpopulations in the USA (eg, other American Indian subpopulations and Pacific Islanders). Fourth, the additional information we provide for each cohort (eg, whether the cohort has geocoded data) is not exhaustive. Future efforts could expand the information provided on each cohort to allow more comprehensive searches. Lastly, the information presented in RIS Atlas is only representative of cohort data collection efforts through 2014, although we have begun to add more current data.

Despite these limitations, our work represents the first systematic assessment of $\mathrm{R} / \mathrm{S}$ survey items currently available within NIH-funded cohort studies, and addresses several barriers to better understanding the impact of R/S on health. RIS Atlas enables investigators to easily identify novel $\mathrm{R} / \mathrm{S}$ analyses that could be conducted across multiple cohort studies. The RIS Ontology, constituting the conceptual structure of RIS Atlas, also facilitates harmonising R/S survey items across cohorts, offering a framework for tracking and comparing items by conceptual category across additional cohort studies. Our hope is that RIS Atlas will facilitate additional high-quality, prospective studies of $\mathrm{R} / \mathrm{S}$ and health in cohort study populations.

\section{Author affiliations}

${ }^{1}$ Harvard/MGH Center on Genomics, Vulnerable Populations, and Health Disparities, Massachusetts General Hospital, Boston, Massachusetts, USA

${ }^{2}$ School of Anthropology and Museum Ethnography, Oxford University, Oxford, UK ${ }^{3}$ School of Medicine, University of Nevada Las Vegas, Las Vegas, Nevada, USA ${ }^{4}$ Harvard Medical School, Boston, Massachusetts, USA

${ }^{5}$ Westmont College, Santa Barbara, CA, USA

${ }^{6}$ Chesapeake Regional Information Systems for our Patients, Columbia, MD, USA ${ }^{7}$ Department of Psychology, Bowling Green State University, Bowling Green, Ohio, USA

${ }^{8}$ Inamori International Center for Ethics, Case Western Reserve University, Cleveland, Ohio, USA

Contributors $A B S, B S, L M$, and AES led the systematic content analysis. ABS, MAA, BS, LM, and AES developed the RIS Atlas database, with conceptual input from KIP and LGU, and technical input from PT and ATM, on development and refinement of the ontology. BVK contributed to further refinements of the database and ontology categories after initial drafts were completed. MM created the RIS Atlas website and implemented all backend work on the website. ABS, MAA, MM, and AES contributed to the design and functionality of the website. $\mathrm{ABS}, \mathrm{MAA}, \mathrm{BS}, 00 \mathrm{I}, \mathrm{BVK}$, and $\mathrm{AES}$ contributed to writing and developing the manuscript.

Funding This study was funded by a grant (\#48424) from the John Templeton Foundation (AES). The funder had no role in the design of the study; the collection, analysis, and interpretation of data; nor in the writing of the manuscript.

Competing interests None declared.

Patient and public involvement Patients and/or the public were not involved in the design, or conduct, or reporting, or dissemination plans of this research.

Patient consent for publication Not applicable. 
Ethics approval As our research activities with the cohort studies were limited to content analysis of cohort survey questionnaires, this work is not considered human subjects research. Therefore, research ethics approval was not pursued or obtained.

Provenance and peer review Not commissioned; externally peer reviewed.

Data availability statement Data are available in a public, open access repository. Aggregate, cohort-level data are available to search and download via the RIS Atlas website (https://atlas.mgh.harvard.edu/). The RIS Atlas database is also archived permanently with more limited search functionality in Harvard Dataverse (https:// doi.org/10.7910/DVN/6WFCL5), a public, open access repository. Individual-level data are available for analysis upon contacting the relevant cohort(s). Researchers will need to obtain ancillary study approval, execute appropriate data use agreements and receive institutional review board approval (or equivalent) before individual-level data can be accessed from cohorts

Open access This is an open access article distributed in accordance with the Creative Commons Attribution Non Commercial (CC BY-NC 4.0) license, which permits others to distribute, remix, adapt, build upon this work non-commercially, and license their derivative works on different terms, provided the original work is properly cited, appropriate credit is given, any changes made indicated, and the use is non-commercial. See: http://creativecommons.org/licenses/by-nc/4.0/.

Author note NIH funding statistics were gathered using NIH RePORTER version 7.41 .0 (https://projectreporter.nih.gov/reporter.cfm) on April 18, 2020. The following search terms for R/S-related projects were used to search all project abstracts and titles for fiscal year 2019: Religion OR religious OR religiosity OR spiritual OR spirituality OR Buddhism OR Confucian OR Hindu OR Shinto OR Sikh OR Islam OR Muslim OR Judaism OR Taoism OR Daoism OR Bible OR church OR mosque $O R$ synagogue $O R$ ecumenical $O R$ theology $O R$ theological $O R$ rabbi $O R$ priest $O R$ minister OR swami OR gurdwaras $O R$ ashram $O R$ pray $O R$ prayer $O R$ meditation $O R$ worship OR God OR Allah. The terms 'Christian,' 'Jewish,' 'Jain,' and 'temple' were omitted because they retrieved projects unrelated to R/S with these terms in the names of hospitals, universities, and investigators listed. Results showed that 171 R/S-related projects were awarded a total of $\$ 73,001,180$ in 2019 , compared with a total of $\$ 36,206,577,792$ in $2019 \mathrm{NIH}$ funding across 66,918 projects.

\section{ORCID iDs}

Anna Boonin Schachter http://orcid.org/0000-0003-3015-5014

M Austin Argentieri http://orcid.org/0000-0003-0242-853X

Oluwaseyi 0 Isehunwa http://orcid.org/0000-0001-6439-0026

Blake Victor Kent http://orcid.org/0000-0003-0782-9041

Alexa T McCray http://orcid.org/0000-0001-7936-8956

\section{REFERENCES}

1 Idler EL. Religion as a social determinant of public health. Oxford: Oxford University Press, 2014.

2 Koenig H, King D, Carson VB. Handbook of religion and health. Oxford: Oxford University Press, 2012.

$3 \mathrm{Li} \mathrm{S}$, Okereke OI, Chang S-C, et al. Religious service attendance and lower depression among Women-a prospective cohort study. Ann Behav Med 2016;50:876-84.

4 Ronneberg CR, Miller EA, Dugan E, et al. The protective effects of religiosity on depression: a 2-year prospective study. Gerontologist 2016;56:421-31.

5 Zehnder D, Prchal A, Vollrath M, et al. Prospective study of the effectiveness of coping in pediatric patients. Child Psychiatry Hum Dev 2006;36:351-68.

6 Kleiman EM, Liu RT. An examination of the prospective association between religious service attendance and suicide: explanatory factors and period effects. J Affect Disord 2018;225:618-23.

7 VanderWeele TJ, Li S, Tsai AC, et al. Association between religious service attendance and lower suicide rates among US women. JAMA Psychiatry 2016;73:845-51.

8 Cozier YC, Yu J, Wise LA, et al. Religious and spiritual coping and risk of incident hypertension in the black women's health study. Ann Behav Med 2018;52:989-98.

9 Charlemagne-Badal SJ, Lee JW. Religious social support and hypertension among older North American Seventh-Day Adventists. $J$ Relig Health 2016;55:709-28.

10 Salmoirago-Blotcher E, Fitchett G, Hovey KM, et al. Frequency of private spiritual activity and cardiovascular risk in postmenopausal women: the women's health Initiative. Ann Epidemiol 2013;23:239-45.

11 Cline KMC, Ferraro KF. Does religion increase the prevalence and incidence of obesity in adulthood? J Sci Study Relig 2006;45:269-81.
12 VanderWeele TJ, Yu J, Cozier YC, et al. Attendance at religious services, Prayer, religious coping, and Religious/Spiritual identity as predictors of all-cause mortality in the black women's health study. Am J Epidemiol 2017;185:515-22.

13 Li S, Stampfer MJ, Williams DR, et al. Association of religious service attendance with mortality among women. JAMA Intern Med 2016;176:777-85.

14 Schnall E, Wassertheil-Smoller S, Swencionis C, et al. The relationship between religion and cardiovascular outcomes and allcause mortality in the women's health Initiative observational study. Psychol Health 2010;25:249-63.

15 Chen Y, VanderWeele TJ. Associations of religious Upbringing with subsequent health and well-being from adolescence to young adulthood: an Outcome-Wide analysis. Am J Epidemiol 2018;187:2355-64.

16 Seawell AH, Toussaint LL, Cheadle ACD. Prospective associations between unforgiveness and physical health and positive mediating mechanisms in a nationally representative sample of older adults. Psychol Health 2014;29:375-89.

17 Krause N, Hayward RD. Prayer beliefs and change in life satisfaction over time. J Relig Health 2013;52:674-94.

18 Krause N. Religious involvement, humility, and self-rated health. Soc Indic Res 2010;98:23-39.

19 Astin JA, Beckner W, Soeken K, et al. Psychological interventions for rheumatoid arthritis: a meta-analysis of randomized controlled trials. Arthritis Rheum 2002;47:291-302.

20 Bhasin MK, Dusek JA, Chang B-H, et al. Relaxation response induces temporal transcriptome changes in energy metabolism, insulin secretion and inflammatory pathways. PLoS One 2013;8:e62817.

21 Saatcioglu F. Regulation of gene expression by yoga, meditation and related practices: a review of recent studies. Asian J Psychiatr 2013;6:74-7.

22 Black DS, Cole SW, Irwin MR, et al. Yogic meditation reverses $\mathrm{NF}-\mathrm{KB}$ and IRF-related transcriptome dynamics in leukocytes of family dementia caregivers in a randomized controlled trial. Psychoneuroendocrinology 2013;38:348-55.

23 Shields AE, Balboni TA. Building towards common psychosocial measures in U.S. cohort studies: principal investigators' views regarding the role of religiosity and spirituality in human health. $B M C$ Public Health 2020;20.

24 Ellison CG, Fang O, Flannelly KJ, et al. And mental health: exploring the Moderating effects of religious identity. researcharticle. The International Journal for the Psychology of Religion 2013;23:214-29.

25 Exline JJ, Pargament KI, Grubbs JB, et al. The religious and spiritual struggles scale: development and initial validation. Psycholog Relig Spiritual 2014;6:208-22.

26 Nolan JA, McEvoy JP, Koenig HG, et al. Religious coping and quality of life among individuals living with schizophrenia. Psychiatr Serv 2012;63:1051-4.

27 Pargament K, Feuille M, Burdzy D. The brief RCOPE: current psychometric status of a short measure of religious coping. Religions 2011;2:51-76.

28 Scandrett KG, Mitchell SL. Religiousness, religious coping, and psychological well-being in nursing home residents. J Am Med Dir Assoc 2009;10:581-6.

29 Tarakeshwar N, Vanderwerker LC, Paulk E, et al. Religious coping is associated with the quality of life of patients with advanced cancer. $J$ Palliat Med 2006;9:646-57.

30 Berkman LF, Syme SL, networks S. Social networks, host resistance, and mortality: a nine-year follow-up study of Alameda County residents. Am J Epidemiol 1979;109:186-204.

31 Abeles R, Ellison C, George L. Multidimensional measurement of religiousness/spirituality for use in health research. A report of the Fetzer Institute/National Institute of aging working group. Kalamazoo, Ml: Fetzer Institute, 1999.

32 Idler EL, Musick MA, Ellison CG, et al. Measuring multiple dimensions of religion and spirituality for health research. Res Aging 2003;25:327-65.

33 Pargament KI, Silverman W, Johnson S, et al. The psychosocial climate of religious congregations. Am J Community Psychol 1983:11:351-81.

34 Carver CS, Scheier MF, Weintraub JK. Assessing coping strategies: a theoretically based approach. J Pers Soc Psychol 1989;56:267-83.

35 Addison CC, Campbell-Jenkins BW, Sarpong DF, et al. Psychometric evaluation of a coping strategies inventory short-form (CSI-SF) in the Jackson heart study cohort. Int J Environ Res Public Health 2007;4:289-95

36 Underwood LG, Teresi JA. The daily spiritual experience scale: development, theoretical description, reliability, exploratory factor 
analysis, and preliminary construct validity using health-related data. Ann Behav Med 2002;24:22-33.

37 Koenig HG, Büssing A. The Duke university religion index (DUREL): a five-item measure for use in epidemological studies. Religions 2010;1:78-85.

38 Brintz CE, Birnbaum-Weitzman O, Merz EL, et al. Validation of the functional assessment of chronic illness therapy-spiritual well-beingexpanded (FACIT-Sp-Ex) across English and Spanish-speaking Hispanics/Latinos: results from the Hispanic community health Study/Study of Latinos sociocultural ancillary study. Psycholog Relig Spiritual 2017;9:337-47.

39 Mccullough ME, Emmons RA, Tsang J-A. The grateful disposition: a conceptual and empirical topography. J Pers Soc Psychol 2002;82:112-27.

40 McCarthy EP, Pencina MJ, Kelly-Hayes M, et al. Advance care planning and health care preferences of community-dwelling elders: the Framingham heart study. J Gerontol A Biol Sci Med Sci 2008;63:951-9.
41 Sims M, Wyatt SB, Gutierrez ML, et al. Development and psychometric testing of a multidimensional instrument of perceived discrimination among African Americans in the Jackson heart study. Ethn Dis 2009;19:56-64.

42 Cuéllar I, Arnold B, González G. Cognitive referents of acculturation: assessment of cultural constructs in Mexican Americans. $J$ Community Psychol 1995;23:339-56.

43 Pargament KI, Koenig HG, Perez LM. The many methods of religious coping: development and initial validation of the RCOPE. J Clin Psychol 2000;56:519-43.

44 Mascaro N, Rosen DH, Morey LC. The development, construct validity, and clinical utility of the spiritual meaning scale. Personality and Individual Differences 2004;37:845-60.

45 Luckow A, Ladd KL, Spilka B. The structure of prayer: Explorations and confirmations. In: Hill PC, Hood RW, eds. Measures of religiosity; Paper presented at the meeting of the American Psychological Association. Toronto, Canada: Religious Education Press, 1999: 70-2. 